\title{
Identidades en globalización
}

El proceso de globalización en curso, ¿implica también la formación de "identidades globales" en sentido propio y no sólo metafórico?Algunos autores así lo piensan,

e incluso han pretendido definir los elementos culturales que, en su opinión, compartimos todos a nivel mundial y que fundamentarían en todos los habitantes del orbe un "sentido de pertenencia global". Algunos incluso hablan de la formación de una "clase media mundializada". El presente trabajo señala la debilidad de los argumen-

tos esgrimidos en todos estos casos y

sostiene que incluso los movimientos destinados a generar una o pinión pública mundial (organizaciones ecologistas, de derechos humanos, etc.) siguen atrapados en la malla del sistema de Estados-naciones y de sus intereses.Y lo que suele presentarse como "cultura global" no es más que la cultura dominante de ciertas partes del globo (Estados U nidos, Europa, Japón) a la que no todos los habitantes del planeta tienen igual acceso.

$\downarrow$ Instituto de Investigaciones Sociales de la Universidad $\mathrm{N}$ acional Autónoma de México gilberto@ servidor.unam.mx líticos, cuando se intenta pensar los procesos de globalización bajo el ángulo de una teoría de las identidades sociales? Ésta es la cuestión que me propongo abordar con ustedes en el presente ensayo en términos exploratorios.

No se me escapa el hecho de que la noción de identidad es de manejo delicado para las ciencias sociales y, además, políticamente peligrosa. Es de manejo delicado por la necesidad de rescatarla de la banalización y de las trampas del sentido común que ti ende a representarla como una entidad homogénea, cristalizada y substancial. Y es políticamente peligrosa por su aptitud para integrar mitos políticos con fuertes resonancias pasionales, como en el caso de los nacionalismos, de los etno-nacionalismos y de los racismos de toda laya. ${ }^{1}$ Pero, pese a todo, sigue siendo una noción imprescindible en las

1 Pueden existir "identidades asesinas", como lo demuestran los conflictos étnicos que desembocan en la dinámica irracional de las "limpiezas étnicas". Véase a este respecto A mín Maalouf, 1998. 
ciencias sociales, no sól o porque ha venido a potenciar la teoría del actor, de la acción social y, particularmente, de la acción comunicativa, sino también porque permite recuperar, un poco por la puerta trasera, la noción de cultura que en los últimos tiempos ha sido objeto de una cerrada crítica desconstruccionista por la llamada "antropología posmoderna" (Clifford y Marcus, 1986; Clifford, 1991; Pasquinelli, 1993).

Desde una perspectiva estrictamente relacional y situacionista -que excluye toda connotación fijista o esencialistaentiendo aquí por identidad el conjunto de repertorios culturales interiorizados (representaciones, val ores, símbol os...) a través de los cuales los actores sociales (individual es o colectivos) demarcan simból icamente sus fronteras y se distinguen delos demás actores en una situación determinada, todo ello en contextos históri camente específicos y socialmente estructurados.

Según la sociología clásica - de Max Weber y Georges Simmel a Talcott Parsons y R.E. Park-, los actores sociales tienen acceso a esos repertorios identificadores y diferenciadores a través de su pertenencia -subjetivamente asumidaa diferentes tipos de col ectivos, sean éstos grupos, redes sociales o grandes colectividades como las "comunidades imaginadas" de Benedict Anderson (1991). Así, a través de nuestra pertenencia a una I glesia nos apropiamos, al menos parcialmente, de su repertorio simbólico-cultural (credo, dogmas, sistema ritual...) para definir la dimensión religiosa de nuestra identidad. Más aún, nuestra pertenencia religiosa se define precisamente por esta apropiación intersubjetivamente reconocida (Pollini, 1990:186 y ss.).

De acuerdo a lo dicho, nuestro problema puede reformularse en los siguientes términos: ¿Existe una comunidad global, en sentido propio y no sólo figurado, a la cual se pueda pertenecer en diversos grados y formas mediante la apropiación subjetiva de un complejo simbólico-cultural que por fuerza tendría que ser también gl obal?; ¿o más bien habría 
que hablar de múltiples identidades gl obales construidas en torno a intereses monotemáticos y sectoriales, aunque de alcance gl obal, como en el caso de los movimientos ecologistas, pacifistas, anti-nudeares y otros por el estilo?

Entre los teóricos de la globalización no faltan los que afirman no sólo la existencia, sino también la intensificación y la ampliación creciente de un sentido depertenencia gl obal ("a sense of gl obal bel onging") que implicaría la percepción del mundo como una comunidad gl obalizada. ${ }^{2}$ Así, según Roland Robertson (1992:25-27), Ia conciencia global del mundo como un todo, al imentada por experiencias inducidas a través de los media y estimulada por las primeras fotografías de la tierra desde el espacio, habría al canzado un nivel de masa a partir de los años setenta. En consecuencia, estaríamos presenciando la intensificación de la toma de conciencia del mundo como un "lugar único y singular que todos compartimos" (the world as a single place) (p. 132). Anthony Giddens (1990), por su parte, afirma que, en virtud de la globalización - que sería un fenómeno inherente a la modernidad tardía (late modernity)-, estamos viviendo en un mundo

2 Los autores a los que nos referiremos a continuación no utilizan el concepto de comunidad en el sentido tradicional po pularizado porTönnies (y no inmune de connotaciones románticas), es decir, como una solidaridad grupal localmente arraigada y alimentada por relaciones cara a cara, que se opondría a la "sociedad" entendida como asociación racional, abstracta y orientada a fines instrumentales, sino en un sentido más amplio, desligado de toda referencia territorial y de toda idea de proximidad. La condición mínima para que pueda hablarse de comunidad sería la existencia de "experiencias compartidas" (Giddens, 1990:141) simultánea y cálidamente por cierto número de personas, lo que puede darse también a distancia entre individuos y grupos territorialmente muy dispersos, gracias a las técnicas modernas de comunicación. En este mismo sentido,A nderson (1991) habla de la nación como una "comunidad imaginada" que se caracteriza por el sentimiento compartido de una "profunda camaradería horizontal". 
"sin otredades" (a world without others"). ${ }^{3}$ En efecto, según este autor (1991), "la modernidad tardía produce una situación en la que la humanidad deviene bajo ciertos aspectos un solo "nosotros" que afronta problemas y oportunidades respecto a los cuales no existen a 'otros"' (p. 27). En su conjunto, estos planteamientos convergen en la idea de una "aldea global" con todas sus resonancias utópicas.

Ahora bien, ¿qué es lo que se comparte a nivel global en términos de intereses materiales o simbólicos para hablar en sentido propio de una "comuni dad gl obal" o, lo que es lo mismo, de un "sentido de pertenencia gl obal"?

Giddens responde, siguiendo a V. Beck (1992), que lo que nos une globalmente es un sentimiento común de riesgo ante la posibilidad y la probabilidad de catástrofes ecológicas. La percepción generalizada de que "Chernobyl está en todas partes" pondría de manifiesto que no existen "otros", sino sól o un "nosotros" en relación con los riesgos ecológi cos. Y lo que se dice de los riesgos nucleares puede extenderse a los riesgos de contaminación ambiental como resultado de la industrialización. Se trata siempre de riesgos que no conciernen sól o a los profesionales o a los pobres, sino absolutamente a todos los habitantes del planeta, cualquiera que sea su condición de clase, ya que "la pobreza es jerárquica, pero la contaminación es democrática" (Beeck, 1992:36). En resumen, tanto para Giddens como para Beeck, nuestra conciencia del mundo sería, antes que nada, la conciencia de una "comunidad global de riesgo" en la que todos estamos embarcados.

J ohn Tomlinson (1996:78-79) ha señalado, con razón, que el simple hecho de compartir con otros un sentimiento (casi siempre difuso) de ansiedad o de temor frente a riesgos ecológicos planetarios resulta insuficiente para generar la expe-

3 En realidad, G iddens plantea un juego dialéctico entre fuerzas unificadoras y fuerzas disgregativas de la modernidad. Aquí nos referimos sólo al momento unificador de esta dialéctica. 
riencia de un "nosotros" gl obal. En todo caso podría generar - dice este autor- un "sentido débil de comunalidad global" que, por su carácter frágil precario, es incapaz de desembocar en una voluntad política o en acciones concertadas para conjurar los riesgos en cuestión. Nosotros añadiríamos, siguiendo a Parsons y a los teóri cos de la Escuela de Chicago, que el interés compartido por evitar la destrucción del propio nicho ecológico no rebasa el nivel de las relaciones meramente simbióticas, común a todos los organismos vivos, y no sólo a los humanos. Se trata de un nivel inferior al de las relaciones propiamente simbólicas, que son las requeridas para la emergencia de un verdadero sentido de pertenencia sociocultural (Pollini, 1990:187-188).

Para que surja un sentido de pertenencia gl obal se requiere al go más que un mero sentimiento de riesgo o de amenaza común: como dice Tomlinson, se requiere una "comunal idad" más fuerte y positiva, que sólo puede ser la que se define en términos simbólico-culturales.

3

Responde a esta exigencia la propuesta de algunos comunicólogos, según los cuales, el referente cultural del sentimiento de pertenencia global debe buscarse en la cultura mass-mediática, es decir, en la cultura gl obalmente difundida por los medios de comunicación masiva. El mundo debería concebirse entonces como una comunidad global "mass-mediada".

Para ejemplificar el potencial unificador de las redes mundiales de comunicación, estos autores evocan la experiencia de participación gl obal producida por la transmisión en vivo de ciertos eventos de masa vía satélite, como los organizados en los años ochenta por Band Aid, Sport Aid, Live Aid y el movimiento Free Mandela (Hebdige: 1989, 91, citado por Tomlinson, 1996:80). Lo que es más: muchos de estos 
eventos habrían tenido un contenido moral de alcance universal. David Morley (1992) comparte esta misma visión cuando afirma que

"Las informaciones nocturnas de la televisión o una telenovela de larga duración regularmente sintonizadas... [funcionan] como un discurso que construye colectividades a través de la producción no sólo de un sentido de 'participación' en experiencias simultáneas, sino también en el sentimiento de un 'pasado compartido'"' (p.287; citado por Tomlinson, 1996:82).

Son múltiples los argumentos que contribuyen a poner en duda el supuesto poder identificador de la "cultura massmediada" a nivel gl obal. En primer lugar, los propios comunicólogos suelen señalar el carácter efímero, superficial y transitorio de las alianzas ocasional es suscitadas por los me dia en el ámbito de sus respectivas audiencias, por extensas que éstas sean (Hebdige, 1989:91). En segundo lugar, si bien se puede aceptar que los media nos han abierto al ancho mundo y constituyen instrumentos poderosos para reforzar y alimentar identidades colectivas preexistentes, como las nacionales, por ejemplo, hay que poner en duda su capacidad de crear "ex nihilo" identidades colectivas. Esta incapacidad radica, según Tomlinson (1996:84), en el tipo de experiencia y de comunicación que pueden proporcionar los mass-media: se trata siempre, sobre todo en el caso de la tel evisión, de un modo de comunicación monológica, y no dialógica. Y resulta francamente difícil concebir una comunidad fundada en relaciones puramente monológicas, sin reciprocidad y sin la posibilidad de un mínimo de intercambio dialógico entre los actores sociales.

Pero el argumento decisivo es el carácter problemático del supuesto en que se apoya la opinión aquí impugnada, esto es, la suposición de que, a nivel de recepción, el discurso de los media es interpretado del mismo modo en el mundo entero. 
En efecto, si pudiera comprobarse que los media producen a escala global sujetos que interpretan el mundo de manera similar, entonces sí podría afirmarse que producen "identidades gl obalizadas" en sentido propio. Pero, como veremos más adelante, lo que se ha comprobado en términos empíricos es exactamente lo contrario: los procesos de producción y de circulación de los mensajes son, efectivamente, globales, pero su apropiación adquiere siempre un sentido local mente contextualizado.

4

Finalmente, en un plano científicamente menos pretensioso, muchos identifican la "comunidad gl obal" con una supuesta "clase media mundializada" (Lévy, 1998:364), constituida por una élite urbana y cosmopolita sumamente abierta a los cambios de escala, que habla inglés y comparte modos de consumo, estilos de vida, empleos del tiempo y hasta expectativas biográficas similares. Sería la élite que tanto en Tokio como en Buenos Aires, Los Angeles, Londres, Ciudad de México, São Paulo y Bombay "se sientan en canapés del mismo estilo para ver las mismas emisiones de televisión y usan zapatos de tenis de la misma marca para practicar la misma dase de deportes" (p. 364). De modo muy semejante, J onathan Friedman (1994) habla de una estructura mundial de clases que habría generado una "élite internacional constituida por altos di plomáticos, jefes de Estado, funcionarios de organismos humanitarios mundiales y representantes de organizaciones internacionales tales como las Naciones Unidas, que juegan al golf, cenan y toman cocktail juntos, formando una especie de cohorte cultural" (p. 206). Dentro de este esquema, la identidad global por excelencia podría ser la del cosmopolita, un personaje de enorme movilidad que relativiza su pertenencia nacional y circula incesantemente por todas las culturas. 
No cabe duda de que se puede hablar legítimamente de una clase media citadina mundializada. Pero no hay que olvidar que, en este caso, sól o se está detectando una categoría social abstracta - una "clase teórica", diría Bourdieu (1994: 25-27)-, pero no una dase real capaz de movilizarse como un actor colectivo dotado de identidad propia. En efecto, sería sorprendente postular sentimientos compartidos y una solidaridad de clase real entre dos ejecutivos situados en lugares muy distantes, digamos el uno en Nueva York y el otro en $\mathrm{H}$ ong Kong, aunque vistan la misma marca de pants y estén sentados en poltronas del mismo estilo para ver el mismo programa de televisión.

Los actores reales que podemos observar en el escenario global son de naturaleza muy diferente. Se trata de instituciones, organizaciones y movimientos sociales muy variados que conjuntamente parecen constituir un embrión de sociedad civil global y buscan generar una opinión pública mundial sobre acontecimientos mayores en el mundo o, por el contrario, sobre casos singulares pero emblemáticos: presos de conciencia, masacres étnicas, catástrofes naturales, "mareas negras", etc. Según J acques Lévy, estos actores sociales tienden a funcionar como "partidos mundiales". Citemos, por ejemplo, a instituciones como la I glesia católica, que interviene incesantemente tomando posiciones sobre un vasto campo de problemas mundiales; o los llamados "nuevos movimientos religiosos", que han sabido adaptarse admirablemente a la mundialización formando redes elásticas y descentralizadas en el mundo entero, como los "evangelismos" de estilo americano. Pero hay que señalar sobre todo a las organizaciones "monotemáticas" de vocación generalista que se interesan en un sol o tipo de problemas (promoción de los derechos humanos, acciones humanitarias, protección del medio ambiente, etc.) y que, en su mayoría, han recibido el estatuto de organizaciones no gubernamentales (ONG) de parte de las Naciones Unidas. 
Lo que caracteriza a estos "partidos mundiales" es el hecho de que, a pesar de su vocación general ista y de sus objetivos supranacionales, se encuentran irremediablemente entrampados en la estructura internacional de los Estadosnaciones. Por lo tanto son, de hecho, organizaciones internacionales, pero no genuinamente gl obales. Lo que significa que difícilmente pueden desligarse de los intereses en juego dentro del sistema de Estados-naciones. Así, por ejemplo, R. Morgan (1984) ha demostrado cómo las pretensiones globalizantes del movimiento feminista -en búsqueda de una "sororidad global"- han sido radicalmente inhibidas por el contexto estructural e institucional del sistema de Estadosnaciones. Lo mismo cabe afirmar del movimiento ecologista: el problema ecológico global tiene siempre modulaciones particulares según los intereses de los Estados, como lo demuestran las peripecias de Green Peace y las tribulaciones de la Conferencia de las Naciones Unidas sobre medio ambiente y desarrollo humano, cel ebrada en Río de J aneiro en 1992 (Leff, 1998:15-28). Y cuando un organismo subsidiario de las Naciones Unidas, como la UNESCO, genera una dinámica genuinamente democrática y global en el campo de la cultura, amenazando los intereses hegemóni cos de naciones como Estados U nidos e I nglaterra, éstas responden de inmediato retirándose del organismo y negándole todo recurso (como ha ocurrido en 1985 y 1986). Lo que quiere decir que estos organismos internacionales toman en cuenta los intereses gl obales sól o en la medida en que no amenacen el status quo y las disimetrías de poder en el seno del sistema de Estados-naciones.

Terminemos este párrafo con una nota sobre la figura del cosmopolita. ¿Constituye realmente un modelo de identidad individual globalizada?

Según Haznnerz (1992:237-251), la figura del cosmopolita implica una actitud frente a la cultura que se contrapone polarmente a la del localista. Como tipo ideal, el localista se- 
ría el que se identifica preferentemente con su cultura local, entendida como cultura anclada territorial mente y dinamizada a través de relaciones interpersonales face to face. EI cosmopolita, en cambio, sería un sujeto de gran movilidad, abierto al contacto con todas las culturas y que, incluso, adopta una actitud positiva respecto a la diversidad misma, es decir, respecto a la coexistencia de diferentes culturas en su experiencia personal. ${ }^{4}$ Tal sería el caso de los diplomáticos, de muchos hombres de negocios y ejecutivos transnacionales y de intel ectuales urbanos que se mantienen en contacto a través de redes gl obales de intercambio cultural y se sienten "como en casa" en ámbitos culturales muy diferentes de los de suyos.

Sin embargo, no basta la movilidad para volverse genuinamente cosmopolita. Los migrantes laborales, los turistas internacionales, los exiliados y los expatriados siguen siendo en su mayor parte "local istas de corazón" y, por ningún motivo, desean desligarse de su lugar de origen. ${ }^{5}$

Desde el punto de vista identitario, difícilmente se puede atribuir al cosmopolita una identidad transcultural y mucho menos global porque, si bien circula entre diferentes mundos culturales, no llega a ser parte de ninguno de ellos. En efecto, participar en una cultura diferente de la propia no significa comprometerse con ella (Hannerz, 1992:240). Instalado en una relación de continua alteridad con respecto a otras identidades, el cosmopolita sól o puede

4 “El genuino cosmopolitismo es, ante todo, una orientación, una voluntad de comprometerse con el $\mathrm{O}$ tro. Se trata de una actitud intelectual y estética de apertura a las experiencias culturales divergentes, una búsqueda de contrastes más que de uniformidades" (Hannerz, 1992:239).

$5 \mathrm{H}$ ennerz nos dice que una gran parte del turismo internacional de nuestros días es del tipo "home-plus", es decir, el confort de mi casa más el sol, el mar, la playa, la vida salvaje, etc. Por eso, una gran parte de la organización del turismo implica orientar a los turistas hacia enclaves especiales donde puedan seguir disfrutando del mismo confort de su lugar de origen y se les ahorren los problemas hermenéuticos derivados de su contacto circunstancial con los "nativos" (p.241). 
desempeñar roles y participar superficialmente en la realidad de otros pueblos. Según Friedman (1995:204), a esto se reduce toda su identidad.

5

Hemos visto que el obstáculo mayor para poder hablar de "identidad global" o de "identidades global es" radica en la dificultad de detectar un repertorio cultural propiamente global, cuya apropiación subjetiva y distintiva por parte de los actores sociales pudiera dar lugar a un sentimiento de pertenencia también global ad intra, y de diferenciación ad extra, con respecto a un "afuera". En efecto, sabemos que toda identidad implica no sól o compartir una memoria y un repertorio de símbolos comunes, sino también establecer fronteras con respecto a un "afuera", a un espacio exterior. ${ }^{6}$ De aquí la conveniencia de afrontar directamente el problema de la relación entre globalización y cultura. Pero antes de entrar en materia no estará de más referirnos brevemente a lo que entendemos por cultura.

En el ámbito de las ciencias sociales se entiende generalmente como "repertorio de pautas de significados", siguiendo una ya antigua propuesta de Clifford Geertz (1973). En esta misma línea, Anthony Schmidt (1992:171) define la cultura simplemente como un repertorio de creencias, estilos, valores y símbolos. Pero hay que añadir de inmediato una distinción estratégica que permite evitar muchos malentendidos: la distinción entre formas interiorizadas y formas objetivadas de la cultura así entendida. O, como dice Bourdieu (1985:91), entre "formas simbólicas" y estructuras mentales interiorizadas, por un lado, y símbol os objetivados bajo la for-

6 Featherstone (1990) señala la dificultad de concebir un espacio exterior a nuestro planeta, sea como factor de contraste, sea como fuente de amenaza global, a no ser en la ficción de invasiones extraterrestres, de guerras interplanetarias y de conflictos intergalácticos (p. 11). 
ma de prácticas rituales y de objetos cotidianos, religiosos, artísticos, etc., por otro.

Esta manera de concebir la cultura implica no disociarla nunca de los sujetos sociales que la producen, la emplean o la consumen. No existe cultura sin sujeto, ni sujeto sin cultura. O dicho de otro modo: todas las manifestaciones culturales tendrían que referirse siempre a un "espacio de identidad". La debilidad de muchos de los análisis consagrados a la globalización de la cultura radica precisamente en la tendencia a privilegiar sus formas objetivadas - productos, imágenes, artefactos, informaciones, etc.- , tratándolas en forma aislada y meramente taxonómica, sin la más mínima referencia a sus usuarios y consumidores en un determinado contexto de recepción. Así, cuando buscamos ejemplificaciones más concretas de la "cultura mundializada" en los trabajos de Renato Ortiz, sólo encontramos una larga lista de lo que él Ilama "íconos" de la mundialización: jeans, T-Shirts, tarjetas de crédito, ropas Benetton, shopping centers, McDonalds, popmusic, computadoras, Marlboro, etc. De aquí a la cosificación de la cultura parece haber muy poco trecho.

Si adoptamos consecuentemente la concepción simbólica de la cultura, asumiendo siempre el punto de vista de los sujetos que se relacionan con ella, podríamos adelantar cierto número de hipótesis que resumen los resultados de algunas investigaciones recientes.

(1) No se puede hablar de una "cultura global" unificada, homogénea y fuertemente integrada, siguiendo el model o de las "culturas nacionales", pero transportado a una escala superior. Ello requeriría la formación de una sociedad política y de una sociedad civil también gl obales, que no se vislumbran ni remotamente en el horizonte.

(2) En el ámbito global, el panorama de la cultura se nos presenta más bien como una inmensa pluralidad de culturas locales crecientemente interconectadas entre sí, aunque siempre jerarquizadas por la estructura del poder (Ortiz, 
1999:47-48), a las que se añaden, también en forma creciente, copiosos flujos culturales desprovistos de una dara vinculación con un determinado territorio. Son las Ilamadas "culturas desterritorializadas", o también "terceras culturas" (F eatherstone, 1992:1), cuyo prototipo sería el intercambi o de bienes, informaciones, imágenes y conocimientos, sustentado por redes gl obales de comunicación y dotado de cierta autonomía a nivel mundial.

(3) Por razones operatorias podemos distinguir, dentro de lo que hemos Ilamado "terceras culturas", dos dimensiones o "perspectivas", en el sentido de Appadurai (1992:296): Ia que corresponde a la cultura de los bienes de consumo de circulación mundial y la que corresponde a las "culturas populares" en sentido americano, es decir, la cultura transportada por los mass media.

(4) La cultura del consumo de productos de circulación mundial ha sido bien analizada por Renato Ortiz en un libro (1997) consagrado íntegramente a este tema. Ortiz plantea correctamente que esta cultura ha venido a desplazar el ethos centrado en el trabajo, el ahorro y el consumo frugal - característico del primer capitalismo inspirado, según Max Weber, en la ética protestante-, para sustituirlo por otro que coloca el confort y el consumo como valores centrales del estilo de vida moderno (p.164). También señala en qué sentido los bienes materiales de consumo llegan a integrarse al orden de la cultura: si bien se trata de objetos preponderantemente funcionales, se comportan también como signos o símbol os expresivos que frecuentemente connotan poder y status y determinan un estilo de vida considerado valioso. ${ }^{7}$ Pero a mi modo de ver no enfatiza suficientemente el acceso desigual, determinado por la estructura de dases, a los bienes de consumo global; $y$, sobre todo, no percibe con suficien-

7 Un automóvil, por ejemplo, no sólo posee un valor instrumental para su usuario, sino también un valor simbólico en la medida en que connota poder y status. 
te claridad -debido quizás a su propensión a reificar la cultura de su "modernidad-mundo"- que los bienes materiales de circulación global adquieren un significado local al ser consumidos en contextos particulares.

Tomemos el caso de un producto como la Coca-Cola, considerado como una especie de metasímbol o de la homogeneización mundial del gusto por algunos académicos charlatanes. Una investigación etnográfica reciente sobre el consumo de esta bebida en Trinidad (Caribe), realizada por Daniel Miller (1998:169-187), revela claramente el significado contextual que adquieren las "formas globales". En efecto, según Miller, la Coca Cola se "nacionaliza" en cierto modo al combinarse con el ron, la bebida nacional por excelencia de la isla (Rum and Coca Cola es el título de un calipso caribeño muy popular), e incluso adquiere connotaciones étnicas particulares al insertarse dentro del paradigma de bebidas que forman parte de la cultura gastronómica local. Así, la Coca Cola se considera como la bebida de los "blancos" (es decir, de los negros refinados), en oposición a la bebida de origen hindú Ilamada Solo, más asociada a lo local-popular, esto es, a la "gente de color". La conclusión es que el sentido del consumo de la Coca Cola no es el mismo en Trinidad, en los sectores populares de Londres, en el J apón y en los países árabes. De donde se infiere que las corporaciones transnacionales controlan ciertamente la producción y la distribución de sus productos, pero no pueden controlar los efectos culturales de los mismos en los contextos locales de consumo. Por eso, el capitalismo opera siempre local mente combinando las demandas I ocales con las que emanan de las estrategias gl obales (p. 177). "Pensar gl obalmente, pero actuar localmente", reza una famosa máxima de Sony.

(5) El ámbito donde aparentemente se manifiesta con mayor claridad la globalización de la cultura es el de la "cultura popular" en sentido americano, es decir, el ámbito de los 
flujos de imágenes, narrativas, dramaturgias, espectáculos, programas musicales, entretenimientos e informaciones transmitidas por las redes mundiales de los media (periódicos, revistas, televisión, cine, cassettes, etc.). La globalización parece afectar aquí tanto a la producción como a la distribución y consumo de este tipo de cultura. En efecto, se puede demostrar fácilmente que la producción está controlada no sólo por grandes corporaciones, sino también por conglomerados transnacionales que abarcan ramos muy diversificados, aunque relacionados entre sí. ${ }^{8}$ Parece indudable, entonces, que la producción internacional de la cultura popular forma parte de un vasto sistema de corporaciones transnacionales. Por lo que toca a la distribución, que permitela disponibilidad de los productos en el mercado mundial, también depende de una impresionante red transnacional (canales de tel evisión, salas de cine, distribuidores minoristas), cuyos propietarios frecuentemente son los mismos conglomerados arriba señalados. ${ }^{9}$ Diríase entonces que la distribución mundial de la cultura popular escapa al control de los gobiernos nacionales, a pesar de las políticas de contención adoptadas por al gunos de ellos (Canadá, Francia...) para proteger su cultura popular nacional. En cuanto al consumo, la globalización también parece evidente. Los mismos artistas, las mismas películas y los mismos programas de

8 Así, N ews Corporation, de Rupert Murdoch, controla la televisión terrestre y satelital, así como también la producción de películas, libros y periódicos en EE.UU., el Reino Unido, Australia y Japón. Sony Corporation, por su parte, es propietaria de Columbia Records,Tri-Star y Columbia Pictures y, en cuanto tal, no sólo tiene derechos sobre un vasto sector de la industria de la grabación de sonidos y de películas, sino también en el de la producción de música de películas y de las bandas de sonido de estas películas. Y no sólo eso: Sony es el mayor productor de equipos de reproducción de sus propios productos ( $C D$, video caseteras). C onsideraciones semejantes pueden hacerse en torno a Disney Corporation.

9 Por ejemplo, Cable N ews N etwork, de Ted Turner, tiene audiencia no sólo en el Kremlin, sino también en las Repúblicas islámicas; y CN N es ahora parte del conglomerado Time W arner, cuyo vice-Presidente es Ted Turner. 
televisión distribuidos por el mismo grupo de corporaciones transnacionales, son consumidos en Londres, New Y ork, París y São Paulo. "EI mundo es nuestra audiencia", reza un slogan de Time Warner. Ahora bien, hay dos maneras de presentar esta aspiración a un consumo global: o bien bajo la forma de una cultura homogénea estandarizada, como opinan muchos comunicólogos; o bien bajo la forma de un multiculturalismo que permitiría a los consumidores seleccionar lo que les interesa dentro de una amplia oferta de formas y estilos culturales, como opinan los teóricos de la posmodernidad.

En un notable trabajo sobre política y cultura popular, J ohn Street (1997) cuestiona vehementemente esta manera de ver las cosas. Su cuestionamiento se apoya en los siguientes argumentos:

(a) Debe rechazarse la idea de que la globalización de la cultura popular sea efecto de fuerzas meramente económicas, resultantes de diversas estrategias de mercado de las corporaciones transnacionales. Las políticas nacionales y hasta las locales -como las de desregulación y apertura indiscriminada del mercado interno- han desempeñado un papel decisivo en el fortalecimiento de las tendencias globalizantes. Por consiguiente, la globalización no es tanto un proceso inevitable, como un verdadero proyecto político (p. 82). Uno de los problemas de las teorías de la gl obalización sería, según Street, su tendencia a ignorar las actividades de nivel inferior que sirven de soporte a los procesos globalizadores y a pasar por alto las conexiones entre lo local, lo nacional y lo global (p. 76).

(b) No existe una "cultura popular gl obal" ni bajo una forma unitaria (teorías de la estandarización), ni bajo una forma multicultural (teorías posmodernas). "E sto no significa - dice Street- negar que el mundo está cada vez más conectado y que existe una mayor interacción entre las culturas, sino sólo que su efecto no es una pluralidad de culturas iguales, ni 
una síntesis armoniosa de las mismas" (p. 72). Lo que se presenta como una cultura global no es más que la cultura dominante de ciertas partes del globo a la que no todos los habitantes del planeta tienen igual acceso. Se trata de una cultura que emerge en su mayor parte de lugares específicos del mundo (América y Europa) y es manufacturada y distribuida por corporaciones radicadas en Estados Unidos, Europa y J apón. F recuentemente, Ios productos de esta cultura ostentan las huellas de su lugar de origen, como lo demuestra la publicidad que invariablemente los acompaña: Audi, Canon, Coca Cola, Hennessy, Levi-Strauss, Master Card, Mobil, Motorola, Mike, Panasonic, Pepsi-Cola, Sony, Shell, Toshiba, etc. Sigue diciendo J ohn Street: "Las culturas siempre son parte de una lucha por el poder, una lucha en la que los recursos (culturales y financieros) no están igualmente distribuidos, de donde resulta que ciertos países y regiones se encuentran indefensos frente a las maniobras del sistema de comercio mundial" (p. 72). Por consiguiente, si alguna configuración hay que atribuirle a la "cultura popular mundial" es la de un "pluralismo jerarquizado" (Ortiz, 1999:47 y ss.) o, lo que probablemente es lo mismo, la de centro/periferia.

(c) Vale también para la cultura popular el principio de que su consumo tiene siempre un significado local y contextual. Con otras palabras, el proceso de globalización puede definir la distribución, pero no el consumo de los productos culturales (p. 73). Esto quiere decir que la idea de una cultura global es también vulnerable frente al argumento de que no existe un proceso gl obal de interpretación cultural. El mismo producto visual o musical no provoca la misma respuesta en todos los lugares donde se le ve o se le oye. En la cultura popular, el contexto de recepción es determinante y vital. J ohn B. Thompson (1995:174) expresa esto mismo de la siguiente manera: "La globalización de las comunicaciones no ha eliminado el carácter localizado de la apropiación. Más bien ha generado un nuevo eje simbólico en el mundo 
moderno, que describiré como el eje de la difusión gl obalizada y de la apropiación localizada". Múltiples investigaciones etnográficas corroboran esta tesis. Por ejemplo, la recepción del jazz en la antigua Unión Soviética; la recepción de la serie televisiva Dallas por diferentes grupos étnicos de I srael, comparando sus respuestas con las obtenidas en Estados Unidos y J apón (Liebes y Katz, 1993); el uso y el significado de los mass media durante la Revolución iraní, comparados con los del período posrevolucionario del régimen islámico, la recepción de la cultura popular de origen occidental en J apón, etc.

J ohn Street conduye de este modo: "Si la «cultura global» es de hecho la cultura de al gunas partes particulares del mundo, y si no existe una forma única de recepción, entonces tenemos que tomar con cautela la pretensión de que hoy nos estamos enfrentando a industrias gl obales. Más bien nos estamos enfrentando a corporaciones que necesitan expandir sus mercados o sus productos básicos. [...] De hecho, el fenómeno de las compañías «gl obales» puede ser una descripción equivocada de la «transnacionalización corporada en un nivel más elevado de magnitud» (Ferguson, 1992:75).

6

De lo dicho hasta aquí se infiere la necesidad de deslindarse de cierta retórica hiperból ica que no sólo da por hecho la emergencia de una cultura gl obal, sino también la cel ebra con acentos triunfal istas y cuasi-utópicos. Me refiero a la retórica discursiva que circula difusamente en el ámbito de las corporaciones transnacionales, de los especial istas en publicidad y de los expertos en marketing. Es así como ha llegado a difundirse una especie de ideología de la comunidad global, proyectada por la publicidad a través de imágenes como éstas: "Un solo mundo de Coca Cola" (a World of Coke), "U nited Colors of Beneton", "Sony is gl obal", etc. Hasta CNN alega 
que su audiencia internacional constituye una verdadera comunidad global.

Frente a exageraciones como éstas, conviene puntualizar cierto número de cuestiones.

En primer lugar, la globalización es un proceso desigual y polarizado que "en su conjunto tiende a reforzar -si no es que a incrementar- la desigual distribución del poder y de las riquezas tanto entre las naciones como a través de las naciones" (McGrew, 1992:76). El "nosotros" gl obalizado invocado por Giddens y otros es en realidad el "nosotros" del mundo desarrollado, incluidos, por supuesto, los segmentos "cosmopolitas" de las sociedades subdesarrolladas.

En segundo lugar, hay que distinguir cuidadosamente la globalización económica o financiera de la globalización de la cultura. La primera es una "gl obalización fuerte", por su carácter sistémico y estructurado, por lo menos si nos atenemos a las teorías del sistema mundial basadas en la economía política (Wallerstein, 1992:31-55). La segunda, en cambio, constituye una "gl obalización débil", incapaz de generar a escala gl obal sujetos que interpreten el mundo de manera similar y que, por lo mismo, se configuren como identidades gl obales. Renato Ortiz (1996) reconoce esta distinción fundamental cuando prefiere hablar de "mundialización", y no de "globalización de la cultura".

En tercer lugar, como la identidad y la cultura siempre son indisociables de un contexto social, la emergencia de una identidad global supondría, como condición de posibilidad, la conformación de una sociedad civil global que, a su vez, no podría concebirse sin la contraparte de una sociedad política global. Y es precisamente esta dimensión política la que se encuentra subdesarrollada en la arena gl obal. Por lo que toca a la sociedad civil y a su correspondiente espacio público, hemos señalado la existencia de numerosas organizaciones y movimientos que pugnan, desde abajo, por una mayor solidaridad mundial y tienden a conformar una opinión pú- 
blica en torno a problemas globales. Pero todo este esfuerzo sigue siendo contrariado por la "jaula de hierro" del sistema de Estados-naciones, con su estructura disimétrica de bloques y de polos hegemónicos. Por lo tanto, por mucho tiempo seguiremos mirando al mundo a través de mediaciones comunitarias, geopolíticas y económicas definidas a escala restringida; es decir, seguiremos mirando al mundo a través del prisma de sus Estados, de sus religiones, de sus diferentes culturas y de sus mercados locales. $E$

Anderson, Benedict, 1991, Imagined Communities, London:Verso Editions and N LB.

Appadurai,Arjun, 1992, Disjunture and Difference in the Global Cultural Economy, en: Mike Featherstone, Global Culture, London: Sage Publications, pp. 295-310.

Beck,U.,1992, Risk society:Towards a new modernity, London:Editorial Sage.

Bourdieu, Pierre, 1985, “Dialo gue à propos de l'histoire culturelle", Actes de la Recherche en Sciences Sociales, $n^{\circ}$ 59, pp. 86-93.

- 1994, Raisons pratiques, París: Seuil.

Cliford, James y Marcus, George, 1986, W riting Culture. The Poetics and Politics of Ethnography, Berkeley, University of California Press.

- 1991, Sobre la autoridad etnográfica, en: C. G eertz, J. Clifford y otros, El surgimiento de la antropología posmoderna, México: Editorial Gedisa, pp. 141-170.

Pasquinelli, Carla, 1993, "Il concetto di cultura tra moderno e postmoderno", Etnoantropología, Año I, N úm. 1, pp. $34-53$ (Edit. Rosenberg \& Sellier,Turín).

Featherstone, Mike (Ed.) 1992, Global Culture, London: Sage Publications.

Ferguson, M., 1992, "The Mythologie about Globalization", European Journal of Communication, 7 (1), pp. 69-94.

Friedman, Jonathan, 1995, Cultural Identity \& Global Process, London: Sage Publications, 
G eertz, Clifford, 1973, The Interpretation of Cultures, N ew York: Basic Bibliografía Books.

Giddens, Anthony, 1990, The Consequences of M odernity, Stanford, C alifornia:Standford U niversity Press.

- 1991, M odernity and self-identity: Selbs and society in late modern age, $C$ ambridge: Polity Press.

H annerz, UIf, 1992, Cosmopolitan and Locals inWorld Culture, en:Mike Featherstone, Global Culture, London:Sage Publications, pp. 237251.

Hebdige, D., 1989, After the masses, en: S. H all y M. Jacques (Eds.), New Times:The changing face of politics in the 1990s, London: Lawrence and W ishart, pp. 76-93.

Leff, Enrique, 1998, Saber ambiental, México: Siglo XXI Editores.

Lévy, Jacques, 1998, Vers une société civile mondiale?, en:Jean C laude Ruano-Borbalan, L'identité, París: Éditions Sciences H umaines, pp. 363-368.

Liebes,Tamar y Elihu Katz, 1993, The Export of M eaning:Cross-Cultural Reading of 'Dallas', C ambridge, Polity Press.

McGrew A., 1992, A global society, en: S. Hall, D. Held yT. McGrew (Eds.), M odernity and its futures, $C$ ambridge: Polity Press, pp. 61116.

Miller, Daniel, 1998, Coca-Cola: a black sweet drink from Trinidad, en: Daniel Miller (Ed.), Material Cultures, C hicago:The University of Chicago Press, pp. 169-187.

Morgan, R., 1984, Sisterhood is global:The international women's movements anthology, $\mathrm{N}$ ew York:A nchor Press/D oubleday.

Morley, D avid, 1992, Television audiences and cultural studies, London: Routledge.

O rtiz, Renato, 1996, Um outro território, São Paulo: Editora O lho d'Àgua.

- 1997, Mundialización y cultura, Buenos A ires:Alianza Editorial.

- 1999, Diversidad cultural y cosmopolitismo, en:Jesús Martín Barbero y otros (Eds.), Cultura y globalización, U niversidad $\mathrm{N}$ acional de Colombia/C entro de Estudios Sociales, pp. 29-52.

Pollini, Gabriele, 1990, Appartenenza socio-territoriale e mutamento culturale, en:Vincenzo Cesareo (a cura di), La cultura dell'Italia contemporanea,Turín:Edizioni della Fondazione $\mathrm{G}$ iovanni A gnelli, pp. 185-225.

Robertson, Roland, 1992, M apping the Global Condition: Globalization as the Central Concept, en: Mike Featherstone, Global Culture, London: Sage Publications, pp. 15-30. 
Bibliografía Smith, Anthony D., 1992, Towards a Global Culture?, en: Mike Featherstone, Global Culture, London: Sage Publications, pp. 171191.

Street, Jo hn, 1997, Politics and Popular Culture, Philadelphia:Temple University Press.

Thompson, John B., 1995, The M edia and Modernity, Standford, California: Standford University Press.

Tomlinson, John, 1996, Global Experience as a Consequence of Modernity, en: Sandra Braman y Annabelle SrebernyMohammadi, Globalization, Communication and Transnational Civil Society, $\mathrm{N}$ ew Jersey: H ampton Press, pp. 63-87

Wallerstein, 1992, Culture as the Ideological Battleground of the M odern W orld-System, en: Mike Featherstone, Global Culture, London: Sage Publications. 